\title{
BORGES: DEL ANACRONISMO AL SIMULACRO
}

\author{
POR \\ SAUL YURKIEVICH \\ Université de Paris, VIII
}

En el origen y en el término de la obra de Borges prima el poema. Quizá en esa música verbal, en esa forma del tiempo que figura los misterios de la memoria y las agonías del anhelo, en esa cadenciosa sujeción a un sistema de símbolos; en esa emotiva fábrica que es, como el casual autor y el lector ocasional, una de las configuraciones del sueño, quizá en la poesía resida la íntima continuidad que vertebra la obra de Borges, el álgebra y la clave de esa circunvalación.

Así como toda literatura principia por el verso, Borges empieza su actividad literaria por la poesía, para acercarse gradualmente a la narrativa, sin entrar del todo en ella o ingresando mediante sus peculiares mixturas, sus ensayos cuentísticos o sus cuentos ensayísticos, sus reseñas narrativizadas, sus ficciones bibliográficas o apologéticas. No las califica de cuentos, para no confundirlas con esos modelos propuestos por el realismo decimonónico, con esos simulacros naturalistas y psicológicos que presuponen la continuidad factual entre texto y extratexto, entre la representación y su pretexto. Y no llama cuentos a estas piezas porque las sabe andróginas o híbridas en tanto relatos.

$\mathrm{Si}$ en el ámbito narrativo Borges se singulariza por estos sugestivos Janos o centauros, por lo lateral o lo limítrofe de sus invenciones, por la transgresión o la mezcla de géneros, por la excentricidad en relación a los polos literarios tradicionales, su poesía se vuelve cada vez más observante, más tributaria de la prosodia clásica; se vuelve cada vez más sólita, más redundante, cada vez más circunscrita a una preceptiva canónica, cada vez más restringida al registro genérico. Su poesía, como su vida, parece tejer y destejer una misma, una cansada historia. Desplaza parecidas palabras en disposiciones semejantes, conserva imágenes y módulos hereditarios, reitera recursos que son de todos y de nadie; 
logra páginas válidas manipulando la limosna que le dejaron los siglos. Apela a un juego simplificado, a la seguridad de lo añejo para forjar versos adamantinos que puedan resistir el desgaste del tiempo:
Pido a mis dioses o a la suma del tiempo
Que mis días merezcan el olvido,
Que mi nombre sea Nadie como el de Ulises,
Pero que algún verso perdure
En la noche propicia a la memoria
$O$ en las mañanas de los hombres ${ }^{1}$.

Versos perdurables que sobrevivan al autor y a su recuerdo, aciertos que serán de ignota procedencia y que volverán, como todo lo perenne, a la fuente donde se originan: la memoria de la lengua que la poesía perpetúa como ningún otro modo de expresión. O quizá Borges recurre a la simpleza técnica para indicar que ella conduce a la grandeza intrínseca.

Borges, poeta cada vez más circular ${ }^{2}$, más tautológico, casi inmóvil en su rotación sin traslación, ensaya las variantes de una combinatoria que paulatinamente restringe su margen de maniobra. Remeda los protocolos, las ceremoniosas reglas de una figuración que antaño fue espejo de un universo unificador, símil de las simetrías de una arquitectura de armónicas distribuciones y equilibrados contrastes. En nuestro universo contingente, desfigurado, en medio del desorden, de la diversidad incoherente, inconciliable, en la boca del horno abrasador, en la víspera de la desintegración, propone un gobierno inmutable, un reloj de príncipes reglado por el eterno retorno. Propone el regreso al orden, el trueque de las aventuras de la invención por las venturas del orden.

Para Borges la realidad es anacrónica, fundamentalmente regresiva; todo progreso es mero espejismo provocado por la ilusoria, por la voluntariosa visión historicista. Borges propicia y practica una poesía anacrónica, quiere reinstalarse en la matriz primigenia del género. Pero sólo puede recuperar la forma, no la esencia de esa idealidad perdida. Por un cambio radical de contexto, la figura ha cambiado de signo. Lo que fue imitación de un modelo que enaltecía la copia se ha convertido hoy en ambiguo simulacro.

Borges experimenta un tránsito gradual del expresionismo inicial al

\footnotetext{
${ }^{1}$ Jorge Luis Borges, «A un poeta sajón», Obra poética (Bueos Aires: Emecé, 1964), p. 247. (En adelante OP.)

2 Véase Saúl Yurkievich, "Borges, poeta circular», Fundadores de la nueva poesia latinoamericana (Barcelona: Barral Editores, 1969), pp. 119-137.
} 
neoclasicismo, patente a partir de $E l$ hacedor. Mientras que en su poesía de impronta ultraísta marca ostentosamente esa modernidad concebida como afán de innovación, como movilidad y mutabilidad formales y focales, como dinamismo intensificador de los efectos, como avecinamientos y altibajos sorprendentes, como imprevisibilidad de dirección, como coqueteo con el dislate y la desfachatez, pronto se modera, censura todo exceso vanguardista, califica su primer estilo de «vanidosamente barroco» y se acoge sumisamente a la preceptiva clásica, a sus convenciones retóricas y simbólicas.

Reincide en la prosodia tradicional retomando los metros y las estrofas más usuales dentro de la versificación española: endecasílabos sujetos a sus constantes acentuales, heptasílabos dependientes de la economía rítmica del endecasílabo, octosílabos en coplas y milongas de inspiración vernácula, y el alejandrino reeditado por los modernistas. Entre las estrofas prima la cuarteta endecasílaba con rima consonante y va en aumento la insistencia en el soneto (a la italiana, con los espacios interestróficos, o a la inglesa, sin ellos).

Borges abandona paulatinamente el verso libre y las formas abiertas, renuncia a ese versículo whitmaniano tan frecuente desde Luna de enfrente (1925) y que casi cesa a partir de El hacedor (1960), única supervivencia de las señas de modernidad abundantes en su poesía juvenil. La poesía amétrica que antes representó el antipasatismo y antiacademicismo de un vanguardista convicto y confeso, que señalaba el deseo de ligar la dicción poética a la lengua oral, se reduce ahora a unos pocos textos cuyo modelo prosódico parece ser la salmodia bíblica o las sagas anglosajonas: "Yo anhelé alguna vez la vasta respiración de los psalmos o de Walt Whitman; al cabo de los años compruebo, no sin melancolía, que me he limitado a alternar algunos metros clásicos: el alejandrino, el endecasílabo, el heptasílabo» ${ }^{3}$.

Borges establece su predio poético dentro del dominio de lo literario propiamente dicho, preestablecido como tal. Se limita a la reedición de las formas éditas, se confina en un espacio donde todas las señales deno$\tan$ y connotan literaridad conforme a los cánones, literaridad centrípeta. La poesía de Borges se parapeta en los usos con linaje literario. Imitador de los monumentos, Borges se cierra al bullicio de afuera, a la diversidad prolifica que circunda las fronteras del reducto literario, que amenaza con invadirlo y confundirlo con el galimatías externo, con la lengua viva, con la lengua promiscua que no cesa de contaminarse y metamorfosearse.

${ }^{3}$ Jorge Luis Borges, Elogio de la sombra (Buenos Aires: Emecé, 1969; 2." ed., 1969), pp. 10-11. (En adelante ES.) 
Borges defiende la literatura literaria de la voracidad entrópica de la otra lengua, de la logorrea de la lengua descentrada y desmedida. Su poesía se vuelve logométrica, aspira a una figura regida por la razón numérica, pretende encerrar el profuso universo dentro de una horma simétrica. A la percepción acompasada, a la visión unitiva corresponden una economía armónica, una isometría concertante. Contra la tremolina externa, Borges dispone su repartimiento repetitivo y reparador. Contra el gran barullo, impone el compás y la síncopa, la sincronía de un tiempo orbital, un mundo péndola, pausado y pautado, oasis de mesura en la desmesura. Contra el revolvimiento, la escansión. Contra la creciente errancia, contra el desorden de lo innumerable y lo ilimitado, contra el fragor del fondo sin ley y sin forma, contra el vértigo o el frenesí, el cubículo, el contador que regla y encuadra su orbe orbicular, el arte de ingenio que regula los centros, los ejes, los acordes, el geómetra que paralela los órdenes, que proyecta perspectivas concordables, que fragua un universo cadencioso, un universo dotado de sentido y en cuya trama el poema tenga su preciso lugar. Dios, en un sueño, revela al tigre que Dante vio y perpetuó en Inferno, $I, 32$, su ignorado destino: «Vives y morirás en esta prisión, para que un hombre que yo sé te mire un número determinado de veces y no te olvide y ponga tu figura y tu símbolo en un poema, que tiene su preciso lugar en la trama del universo. Padeces cautiverio, pero habrás dado una palabra al poema» "

En el plano léxico, Borges abandona la singularización, la localización, la diversificación lingüística. Va atemperando los desniveles de su poesía inicial, que hace ostentación de riqueza, que sobreabunda en cultismos, neologismos y regionalismos, que hace coexistir excéntricamente, en un mismo poema, una plétora expresionista y barroca. Muchos de estos textos desaparecerán de la obra completa, porque Borges prefiere a las máximas variaciones que prefiguran un porvenir las mínimas que pueden recuperar un pasado. Toda coloración idiomática - «exceso de hispanismo o de argentinismo»- será calificada de fealdad, todo neologismo de vana y vanidosa novedad: «El tiempo me ha enseñado algunas astucias: eludir los sinónimos, que tienen la desventaja de sugerir diferencias imaginarias; eludir hispanismos, argentinismos, arcaísmos y neologismos; preferir las palabras habituales a las palabras asombrosas... ${ }^{5}$.

En el plano de las imágenes se nota el mismo tránsito de lo particular a lo general, de lo individual a lo genérico, de la sustancia con su

${ }^{4}$ Jorge Luis Borges, «Inferno, I, 32», El hacedor (Buenos Aires: Emecé, 1960), p. 48. (En adelante $E H$.)

${ }^{5}$ «Prólogo», ES, p. 9; véase también «Prólogo», $O P$, p. 12. 
singularidad cualitativa, concretamente percibida en su despliegue sensual, adensada como materia corpórea o disuelta en haces de sensaciones superpuestas, a la esencia como pura proyección simbólica que transmuta la experiencia directa, los proteicos atributos de la realidad empírica, en modelos ideales, en paradigmas depurados por la sublimación y la estilización. $Y$ el agente de esta decantación, de esta destilación, del pasaje de la materia turbia a la cristalina, el pasaje del aquí y del ahora embrollados, vividos en su tempoespacialidad inmediata, en su confusa mezcla psicosomática, en su implicación existencial, en su inserción en la apremiante urdimbre social, al orden proporcionado, al orbe circular de las regulaciones permanentes, a la previsibilidad, a la legibilidad de lo paradigmático, el agente de transformación de la vívida maraña en metáforas y mitos ejemplares, en arquetipos aptos por siempre y por doquier, es esa memoria imaginaria de la especie, ese quimérico museo, esa conjugación de la retórica con la magia: la literatura. Y si en el origen de lo literario está la poesía, escribirla es para Borges rememorar y remedar las figuraciones, las fabulaciones de la imaginación ancestral. Sólo ese fondo inmemorial, según Borges, asegura la validez, la significación y la eficacia literarias. Ningún acierto puede envanecernos porque no nos pertenece, sólo los errores son nuestros: «Nada me cuesta confesar que he logrado ciertas páginas válidas, pero esas páginas no me pueden salvar, quizá porque lo bueno no es de nadie, ni siquiera del otro, sino del lenguaje o la tradición» ${ }^{\circ}$. La propiedad intelectual, la autoría individual resultan reflejos ilusorios. Nadie puede apropiarse personalmente del lenguaje. Una escritura es o una fortuita combinación de signos o una de las tantas posibilidades combinatorias consentidas por el orden simbólico que las rige. $\mathrm{Y}$ en ese espacio espejeante, uno de sus espejismos es el de la posesión personal de la palabra. De ahí ese rebajamiento en Borges de su condición de autor: «Es trivial y fortuita la circunstancia de que seas tú el lector de estos ejercicios, y yo su redactor» ${ }^{7}$. Por un lado, Borges se considera modesto afluente del gran río de la literatura universal, de la literatura trascendental. (Parafraseándolo, se le puede atribuir lo que dice de Quevedo: «Como Joyce, como Goethe, como Shakespeare, como Dante, como ningún otro escritor (Borges) es menos un hombre que una dilatada y compleja literatura.») Por un lado, Borges escribe bajo la advocación de los inmortales, con reverencia hacia ellos y desdén hacia su propia obra. Por otro, adopta máscaras, practica el simulacro y ejerce un humor irónico (menos frecuente en su poesía que

\footnotetext{
6 «Borges y yo», $E H$, p. 50.

${ }^{7}$ «A quien leyere», $O P$, p. 15.
} 
en su prosa) que lo mantiene inmune al vértigo, al arrebato, ajeno a todo énfasis, a todo exceso de implicación; emplea sus técnicas de distanciamiento que imponen un tanto de ausencia, un margen de lúcido desapego, una escéptica reticencia. En sus manos, el texto se vuelve un juego de espejos, espejos de tinta que al multiplicar anulan la imagen del autor. Borges es a la vez amanuense y hacedor.

También en el orden de las metáforas se va operando el mismo estrechamiento, la reconversión de las metáforas sorprendentes en metáforas itópicas. En las ultraístas, metáforas radicales, las analogías se abren desbordando los marcos de referencia con ejes tan traslaticios que escapan a las limitaciones empíricas:

El madrejón desnudo ya sin una sé de agua

Y la luna atorrando por el frío del alba

$\mathrm{Y}$ el campo muerto de hambre, pobre como una araña ${ }^{8}$.

Luego viene la restricción de las libertades textuales, la retracción hacia lo literario protocolar. Borges renuncia a la libertad de asociación, desecha la imaginación sin ataduras, descree de las metáforas insólitas. Considera que son las prescindibles: meteoritos de conta duración que se extinguen pronto y pronto desaparecen del firmamento poético. Las válidas son las memorables, las arraigadas en la imaginación, las arquetípicas (la vida como río, tela, hilo, sueño, como reflejo del espejo o espejismo). Estas metáforas primordiales desplazarán en los poemas de Borges a las sorpresivas y sorprendentes, a las voltaicas:

Ver en la muerte el sueño, en el ocaso

Un triste oro, tal es la poesía

Que es inmortal y pobre. La poesía

Vuelve como la aurora y el ocaso?

Los símbolos sólitos son, según Borges, los únicos garantes de la validez de un poema. De ahí que reduzca cada vez más su panoplia de alegorías y de emblemas, que reincida, que porfíe en laberinto, sueño, espejo, biblioteca, espada, arena, tigre. «A los espejos, laberintos y espadas que ya prevé mi resignado lector se han agregado dos temas nuevos: la vejez y la ética», reza en el prólogo de Elogio de la sombra. A ellos se añade ahora la ceguera, ceguera valorizada por el abolengo mítico (Tiresias, Edipo) y literario (Homero, Milton, Groussac):

\footnotetext{
${ }^{8}$ «El General Quiroga va en coche al muere», $O P$, p. 80.

9 «Arte poética», $O P$, p. 223.
} 


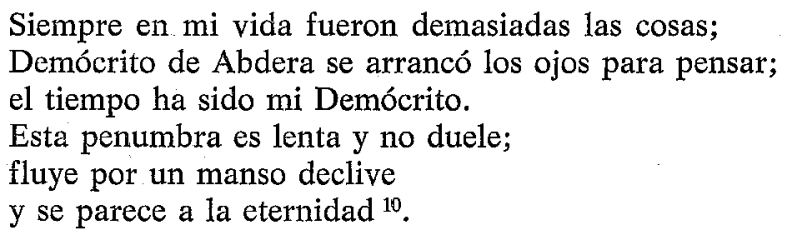

La ceguera lo absuelve del abigarrado y confuso mundo, lo exceptúa de toda novedad. Lo reduce al saber reminiscente donde lugares, caras, cosas, libros quedan fijados en la memoria sin porvenir. $Y$ el tiempo es un regreso y todo converge (o parece converger) hacia su secreto centro. Pienso que sin ceguera física, la actitud de Borges hubiese sido la misma: igual circunscripción, el mismo anacronismo, semejante prescindencia, igual movimiento centrípeto hacia su inasible, su oscura esencia: «a mis años, toda empresa es una aventura / que linda con la noche» ${ }^{11}$.

La poesía de Borges se torna así memorial de la literatura memorable, donde todo escrito halla su razón fundamental en la memoria literaria de su autor. Ningún recuerdo personal puede sobrepasar en importancia a la remembranza de una obra maestra: «Pocas cosas me han ocurrido y muchas he leído. Mejor dicho: pocas cosas me han ocurrido más dignas de memoria que el pensamiento de Schopenhauer o la música verbal de Inglaterra» ${ }^{12}$. Su poesía se constituye con lo extraído del tesoro de la lengua y del museo de las bellas letras; la invención está reducida a la redisposición de esos materiales prefigurádos. Borges cultiva un arte mnemónico, arte añejo que corresponde a una época en que los libros eran pocos y su memoria, dilatada, a la era de la transmisión oral y de la retentiva, anterior a la difusión de la letra impresa. Opera sobre la base de la literatura presente al espíritu, no confiada al soporte material de la escritura, menos releída que rememorada, o releída para refrescar su retención ${ }^{13}$. Y nada mejor para memorizarla que la andadura verbal, que una forma rítmica regular. Nada mejor que la sincronía, que la isometría. Esta mnemotécnica depende de la memoria artificial que sistematizaron los retóricos; apela no a la memoria individual, sino a la colectiva, o mejor dicho, a una memoria que deja de individualizarse para volverse depositaria del fondo común. Borges subordina el repertorio de recuerdos personales, el acervo autobiográfico, la mne-

10 «Elogio de la sombra», ES, p. 155.

11 «Un lector», ES, p. 152.

12 «Epílogo», $E H$, p. 109.

${ }^{13}$ Véase Michel Beaujour, «La mémoire réthorique», en Miroirs d'encre (Paris: Éditions du Seuil, 1980), pp. 81 y ss. 
mónica particular a la mnemotécnica retórica. Desecha la memoria natural y atenúa la presencia personal: reprime la inscripción de la subjetividad. La presencia cultural predomina sobre la del sujeto psicológico. La poesía de Borges es un placentero paseo por los topoi, por los loci del teatro de la memoria, donde se aloja y se despliega la razonada arquitectura del saber.

La poesía de Borges es colecticia, silva de varia lección: abunda en reflejos e interpolaciones. Está hecha de citas, préstamos, imitaciones, o sea, de rememoración. Es, como toda literatura, básicamente apócrifa, compuesta de simulaciones, de disimuladas interpolaciones. Artificioso ensamblaje de figuras y modos preexistentes, ingenioso montaje de textos preformados, es como toda literatura astuto plagio: como toda literatura, es simulacro.

Borges imita los modelos magnos, pero no puede producir copias que hayan interiorizado la semejanza con el original porque coinciden con él en letra y en espíritu, copias-iconos modeladas interiormente por la misma idea ${ }^{14}$. En la era de la sacralidad profanada, de la profanación de los arcanos, en la ciudad moderna, laica, mercantil y pragmática, en la sociedad regida por la cuenta y la razón, que relega el arte a la esfera individual y privada, que lo reduce a pasatiempo apto para satisfacer necesidades accesorias, Borges no puede ser más que solitario pescador de maravillas. No puede sino coleccionar prodigios a través de una lectura desviada, al sesgo, de esos reservorios de portentos que son las literaturas no de inspiración, sino de visión mitológica, a las que acude en busca del estímulo fantástico, de lo apropiable, de lo aprovechable para urdir sus fantasmagorías. Borges no puede sino comerciar con apariencias, no puede alcanzar la esencia subvertida por el ocaso de los dioses. Está condenado al simulacro, a los ídolos degradados, recluidos ahora en el reducto de lo estético. Apela a los símiles que presuponen la solidaridad del orden humano con el natural, la correspondencia de lo divino con lo mundano para aprovechar lo que les queda todavía de poder ritual, aurático, para provocar una suspensión distanciadora del contexto donde el texto se compone y se transmite; se vale de pasados destemporalizados por el apartamiento mítico para provocar esa apariencia de eternidad que el extrañamiento estético infunde. Traslada la figuración a ámbitos legendarios capaces de propiciar de inmediato la mediación mitopoética, pero las claves de ese sortilegio están perdidas. El arte de

${ }^{14}$ Retomo aquí la distinción platónica entre copia-icono y fantasma-simulacro. Véase Gilles Deleuze, "Simulacre et philosophie antique», Logique du sens (Paris: $10 / 18,1973)$, pp. 347 y ss. 
magia ha sido rebajado a arte de ilusión. Antes y ahora, decir lo mismo no es lo mismo por las variantes connotativas impuestas por cortes históricos, axiológicos, epistémicos que modifican fundamentalmente el contexto. El reencuentro con la mentalidad mágica no puede sino ser irónico o paródico; se da fuera del saber de origen. Subsiste la apariencia como efecto exterior del simulacro, que conlleva a la vez coincidencia y divergencia con respecto al modelo. No hay eterno retorno: la semejanza simulada pone en evidencia el funcionamiento peculiar del simulacro, portador de un poder que niega al original y a la copia. No hay por fin ni punto de vista ni jerarquías comunes, no hay tampoco objeto común. La obra resulta un condensado de coexistencias disímiles: reescritura, remake. La simulación, desprendida de su objeto, libera el fantasma, la imagen desfigurante, conductora de alteridades incontrolables, que ocupa el lugar del objeto (en Borges abundan más los fantasmas teológicos y oníricos que los eróticos) para permitir un trato desembarazado con to figural, desembarazado del orden objetual: «lo real se confundía con lo soñado o, mejor dicho, lo real era una de las configuraciones del sueño» ${ }^{15}$. Establecida, como lo hace Borges, la identidad fundamental entre existir, soñar y representar, todo se vuelve figuración fantasmática, teatro de abstracciones, onirogénesis. Para rehuir el odiado sabor de la irrealidad, Borges, diestro en el hábito de simular, juega a ser otro; se deja habitar no por el alma de Homero, de Dante o de Shakespeare, sino por sus fantasmas, hasta agotar las apariencias del ser; pero no hay reencarnación posible: sólo simulacros.

En ese ámbito fantasmático, lo falso revela su potencia. Subvierte el orden, destituye la jerarquía, perturba la fijeza, instaura el mundo de las distribuciones nómadas, siembra la anarquía, se traga todo fundamento, torna espectral cualquier relación entre mente y mundo. El simulacro ficcional vuelve superchería la supervivencia mítica en el seno de una sociedad que la soporta parcialmente y que ha perdido el secreto de las artes de encantamiento. Y a la vez, el simulacro, instigador de fantasmagorías, al liberar de las represiones realistas, despierta las fuerzas ocultas, da paso a los desplazamientos de esa alteridad subyacente que disemina su presencia diversificando el orden semántico. Las máscaras no son inalterables ni los signos impasibles. El entretenimiento se vuelve demoníaco. Por la imposible domesticación de los símbolos, la cosmología, reglada por una preceptiva clásica, vira a pandemonio. Los contenidos latentes pujan por devolver la imagen clara al fondo revuelto, y la coherencia de la representación resulta amenazada por una incontro-

${ }^{15}$ «Parábola del palacio», EH, p. 42. 
lable errancia. Como en Chesterton, las proporcionadas asignaciones pueden convertirse en despropósito: «la valerosa obra de Chesterton, prototipo de la sanidad física y moral, siempre está a punto de convertirse en una pesadilla. La acechan lo diabólico y el horror; puede asumir, en la página más inocua, las formas del espanto» ${ }^{16}$. Bajo la superficie de la fachada apolínea, irrumpen las series divergentes, portadoras de diferencias irreductibles, que ningún principio cohesivo consigue concordar. Ellas imponen la discontinuidad, la discordia de las causalidades incompatibles.

El círculo del eterno retorno se vuelve indefectiblemente excéntrico, con un centro en continuo desplazamiento. La representación cambia de signo. Lo religioso queda despojado de poder epifánico, lo esotérico pierde su capacidad mediúmnica, lo metafísico pierde su proyección numénica. El juego retórico ocupa el lugar de la revelación. Los ídolos son destituidos, descienden rebajados a fenómenos de feria. Los dioses, destronados, degeneran en facinerosos, en mestizos de rasgos achinados, en canalla de lupanar. A la estirpe olímpica se le han atrofiado los rasgos humanos; ya no sabe ni hablar ${ }^{17}$. La regresión hacia lo infrahumano convierte a los olímpicos en animales de presa, los transforma en los caóticos ídolos de la sangre, de la tierra y de la pasión, venerados, según Borges, por una era bajamente romántica como la nuestra. Los majestuosos son descendidos hacia la entraña sanguinolenta, hacia la irracionalidad visceral, hacia esa profundidad que horripila a Borges, hacia «la maciza realidad primordial / de goce y sufrimientos carnales» ${ }^{18}$. Allí caduca la serenidad borgeana, cesa la impasibilidad incorporal: el sentido no puede ya desprenderse, no puede exorcizar las acciones" y pasiones de los cuerpos. Los símbolos también se degradan; la mortífera flecha que nubló el sol en la batalla y permitió al guerrero conquistar nuevas tierras, el lazo que sujetó indómitas bestias, la cruz que fue patíbulo de un dios quedan hoy relegados a la condición de signos inocuos:

Cruz, lazo y flecha, viejos utensilios del hombre, hoy rebajados o elevados a símbolos; no sé por qué me maravillan, cuando no hay en la tierra una sola cosa que el olvido no borre o que la memoria no altere y cuando nadie sabe en qué imágenes lo traducirá el porvenir ${ }^{19}$.

${ }^{16}$ Jorge Luis Borges, «Sobre Oscar Wilde», Otras inquisiciones (1937-1952) (Buenos Aires: Sur, 1952), p. 97. (En adelante OI.)

${ }_{17}$ "Ragnarök», $E H$, p. 47.

18 «El truco», $O P$, p. 27.

19 «Mutaciones», $E H$, p. 37. 
Ni el sueño posee ya la omnipotencia capaz de concebir un tigre malayo. Ni ese transporte hacia la zona del deseo que absuelve del tiempo y del espacio restrictivos permite engendrar el tigre rayado: «Aparece el tigre, eso sí, pero disecado o endeble, o con impuras variaciones de forma, o de un tamaño inadmisible, o harto fugaz, o tirando a perro o a pájaro» ${ }^{20}$.

A través de su diestro, de su obstinado anacronismo, Borges se empeña en salvaguardar las virtudes primigenias del poema, en devolverlo a su fuente y su origen: la memoria retórica y la memoria mítica. Cultiva los efectos clásicos de alejamiento que desvinculan el texto del presente circunstancial y del mundo circundante. Invalida toda noción de actualidad y rehúye su notación. Hace mucho tiempo que renegó de la vanguardia, hace mucho que se cree absuelto de «la obligación del todo superflua de ser moderno». Pocos escritores contemporáneos son objeto de su veneración. Aparte de Whitman, Wilde, Chesterton, Bloy, Yeats y Wells, que consideró finiseculares, no veo sino dos: el decisivo Franz Kafka, que genera a la vez sus sucesores, y sus precursores ${ }^{21}$, a quien Borges traduce, cita, comenta e imita, y James Joyce, cuyo Ulises es doble paradigma de modernidad y de ancestralidad. En "Invocación a Joyce» ${ }^{22}$, lo eleva al rango de modelo de su generación, the lost generation, como la llamó Gertrude Stein. Mientras todos jugaban a ser los Adanes del siglo naciente, adamitas de un mundo auroral que esperaba ser nombrado, mientras todos se agrupaban en ruidosas sectas para reinventar la literatura practicando innovaciones ahora reducidas a ceniza, Joyce, tesonero y riguroso, se aplicaba a la construcción de sus arduos, infinitos laberintos. Ese perdurable dédalo, según Borges, justifica, redime a toda su generación ${ }^{23}$.

A pesar del menosprecio por la vanguardia, Borges guarda la marca del ultraísmo («el ultraísta muerto cuyo fantasma sigue siempre habitándome»), guarda las huellas de aquella literatura hecha de sorpresas dictadas por la vanidad y el azar. No puede dejar de ser moderno, no puede evitar leer y ser leído como contemporáneo de Kafka y de Joyce. Sabe que todo libro está inserto en la textualidad de su época, entretejido con

${ }^{20}$ «Dreamtigers», $E H$, p. 12.

21 Véase «Kafka y sus precursores», $O I$, p. 126.

${ }^{22} E S$, pp. $115-116$.

${ }^{23}$ Borges parece ignorar que el Ulises de Joyce, confrontado en este poema con la modernolatría futurista, consuma magistralmente la instalación de la literatura contemporánea en la modernidad. Parece también ignorar las fecundas innovaciones de ese otro nostálgico de pasados egregios que fue Ezra Pound. La única alusión a Pound la hallo en $O I$, p. 82: «El deliberado manejo de anacronismos, para forjar una apariencia de eternidad, también ha sido practicado por Pound y por T. S. Eliot.» 
la literatura coetánea que condiciona tanto los modos de escritura como de lectura: "Una literatura difiere de otra, ulterior o anterior, menos por el texto que por la manera de ser leída: si me fuera otorgado leer cualquier página actual —ésta, por ejemplo- como la leerán el año dos mil, yo sabría cómo será la literatura el año dos mil» ${ }^{24}$. Sabe que cuando Luciano de Samosata impugna a las deidades olímpicas obra como polemista religioso, y que cuando Quevedo reitera el ataque no hace más que rendir tributo a una tradición literaria. Sabe que puede hacer funcionar el anacronismo como simulacro de eternidad, pero que ninguna regresión, ninguna nostalgia puede devolverlo a los pasados venturosos. $\mathrm{Ni}$ su pasatismo poético, su ausentismo histórico, su protegido jardín gramatical, su culto a lo legendario, su cultivo de teodiceas, sagas, mitologías exóticas, su ocultismo de invernadero, ningún talismán de letras lo preservan por fin de nuestro tiempo. Como nosotros, no escapa a la conciencia escindida, no puede eludir la discontinuidad y la fragmentación que son inherentes a nuestra condición humana. La unidad cognoscitiva está quebrada y lo está también la estética, como han sido fisurados todos los continuos. Sólo un paréntesis candoroso o lúdico, algún interludio fabulador permiten evocar un mundo concordante a contramano de la dispersión, lejos del ruido de fondo sin ley, aparejar una rosácea de palabras, urdir una treta geométrica al margen del desorden, un sistema obediente, una sincronía capaz de contener la agitación plenaria, la vociferación babélica, una cadenciosa quimera contra la nube quemante. También Borges debe asentar sus figuraciones, su cosmología, sobre un ser dislocado y discordante como el nuestro ( Mi vida que no entiendo, esta agonía / De ser enigma, azar, criptografía / Y toda la discordia de Babel») ${ }^{25}$. Si por un lado vislumbra un dios que condesciende al lenguaje que es tiempo sucesivo y emblema, si por un lado presiente un universo unánime donde el poema ocupa su sitial, por el otro se empecina en figurar desdoblamientos anuladores, laberintos sin fin, infinitos negativos, en representar la doble amenaza que desbarata la posibilidad de un mundo humano. La amenaza de abajo: la naturaleza voraz e inextricable, el dislate del instinto, la barbarie irracional, el galimatías del fondo carnal, el indiscriminado maremagno (Borges siente el pavor de lo ignorado, lo entrópico, lo desordenado, lo indiscernible). La segunda amenaza viene de arriba: la abstracción hipostasiada, la irrealidad de la letra y del número librados a su propia funcionalidad, la anemia de la autorreflexión («Dios me ha devuelto al mundo de los hom-

\footnotetext{
24. «Nota sobre (hacia) Bernard Shaw», OI, p. 193.

${ }^{25}$ «Una brújula», $O P$, p. 159.
} 
bres / $\mathrm{A}$ espejos, puertas, números y nombres» ${ }^{26}$ ). Borges sabe que buscar el sentido implica perderlo, implica querer hacer extensivo el orbe del sentido establecido por el hombre, en función de sus propias exigencias mentales, al mundo que está fuera de su conciencia. Entre mente y mundo sólo cabe un acuerdo precario, que permite instrumentar la realidad pero no conocerla. Encima, la razón, ebria de simetría, se solaza en su delirio arquitectónico, tiende a imponer su homogéneo absolutismo, anulador de toda singularidad, su gélido sueño: el imperio del orden funcional, que Borges teme tanto como nosotros. La razón pura, liberada de las especificaciones corpóreas, expulsando de sus formalizaciones los reclamos de la subjetividad, instaura la dominación impersonal del sentido único, del sentido recto. $Y$ la conciencia se extravía en un juego sonámbulo persiguiendo los fantasmas de razón, los espectros de un orden superior que promete falazmente reglamentar el mundo y librar las claves de un conocimiento definitivo.

Borges, antólogo de la literatura infernal, experto en espantos, no puede librarse de ese algo secreto, ciego y central, que en el barro de su yo propende a la pesadilla. Montón de espejos rotos; sabe que ningún orden secreto gobierna el desorden, la incoherencia y la variedad del mundo que estamos compulsados a habitar. Sabe que este mundo oprimente no es una de las formas del sueño, y que su máquina harto compleja gravita aun cuando los soñadores dejen de soñarlo. Constituido, como nosotros, de materia deleznable, de misterioso tiempo, sabe que sus libros nunca lograrán ser impenetrables a la contingencia. Sabe que no hay otro eterno ahora que el que promete la fábula, motivada por la ilimitud del deseo. Sabe que si, por ardid retórico, la cronología puede perderse en un orbe de símbolos, nadie consigue rehuir a su tiempo. Borges está irremisiblemente destinado a ser Jorge Luis Borges, tan real como el mundo de hierro donde ocurren nuestras vidas. Aunque fugue, aunque reniegue, no tiene escapatoria: Borges está condenado a ser nuestro contemporáneo.

${ }^{26}$ «Alexander Selkirk», OP, p. 232. 
